\title{
Analisa Faktor-Faktor Yang Mempengaruhi Kinerja UMKM Wirausaha Wanita Di Kota Manado
}

\author{
LINDA LAMBEY ${ }^{1}$, HERMAN KARAMOY ${ }^{2}$, ROBERT LAMBEY ${ }^{3}$, LINTJE KALANGI ${ }^{4}$ \\ 1,2Program Magister Akuntansi, Fakultas Ekonomi dan Bisnis Universitas Sam Ratulangi \\ email:lindalambey@yahoo.com ${ }^{1}$, hkaramoy@yahoo.com ${ }^{2}$, robert_lambey@yahoo.com ${ }^{3}$
}

\begin{abstract}
This study aims to analyze factors influencing profit growth of small and medium entreprises owned by women in Manado city. This is a quantitative research study. Questionnaires were distributed to 66 respondentse and data were analysed by Ordinary Least Square $(O L S)$. Findings indicate that despite women entrepreneurs can borrow some bank loans, their business profit growth does not increase. High interest rate of their loans may cause the increasing in their expenses which cause the decreasing in their profit. Other problems are they could not manage their business sufficiently due to their incapabilities in managing their capital, financing and accounting systems. On the other hand, access to market information positively and significantly their business profit growth. Given their access to market information, it is possible for them to attain new market share and to compete by providing innovative and customer-oriented products. Thus, their sales revenue and profit can increase. Variable of motivation negatively influences their business profit growth. It is because despite they are highly motivated to run their business, they must prioritize their family over their business and therefore they can not be optimally productive. Nevertheless, entrepreneurship skills can increase their business growth. Their management, accounting, marketing and operating skills can allow them to run and manage their business well, so their profit can increase.
\end{abstract}

Keywords: Women SMEs, profit growth, bank loans, access to market information, motivation, entrepreneurship skills

\begin{abstract}
Abstrak. Tujuan dari penelitian ini adalah untuk menganalisis faktor-faktor yang mempengaruhi kinerja pertumbuhan laba UMKM wirausaha wanita di Kota Manado yang nantinya diharapkan dapat menjadi masukan bagi pemerintah dan pihak terkait untuk membuat kebijakan yang dapat membantu peningkatan kinerja UMKM wirausaha wanita di Kota Manado. Metode analisis yang digunakan adalah metode kausalitas yang menjelaskan mengenai pengaruh akses atas lembaga keuangan, akses UMKM atas informasi pasar, motivasi kerja, serta kemampuan kewirausahaan terhadap peningkatan laba UMKM wirausaha wanita. Untuk melakukan analisis tersebut, digunakan alat analisis regresi berganda dengan metode Ordinary Least Square (OLS). Penelitian ini menggunakan 66 responden. Hasil penelitian menunjukan bahwa kinerja pertumbuhan laba dari UMKM wirausaha wanita di Kota Manado yang memiliki akses ke lembaga keuangan ternyata lebih rendah dibandingkan dengan mereka yang tidak memiliki akses ke lembaga keuangan. Hal ini menunjukkan akses ke lembaga keuangan menurunkan tingkat laba mereka yang disebabkan tingginya bunga yang harus mereka bayar sehingga pendapatan laba mereka menjadi menurun, dan proses dan prosedur pengajuan pinjaman kredit dari bank yang berbelit. Akses informasi terhadap pasar meningkatkan laba UMKM wanita di Manado yang berarti dengan diperolehnya informasi terhadap pasar dapat memberikan kesempatan peluang pasar yang lebih luas bagi wirausaha wanita sehingga dapat meningkatkan omzet penjualan mereka dan laba yang diperoleh. Varibel motivasi kerja para pelaku UMKM wanita berpengaruh negatif terhadap pertumbuhan laba. Hal ini disebabkan para pelaku usaha wanita tidak dapat melepaskan kodrat mereka sebagai ibu dan perempuan yang dapat menurunkan produktivitas mereka. Variabel lainnya yaitu kemampuan menjalankan wirausaha yang memadai dapat meningkatkan pertumbuhan laba. Hal ini berarti kemampuan manajerial dan keuangan yang baik dapat membantu kegiatan operasional UMKM wirausaha wanita secara efisien dan efektif sehingga laba optimal dapat tercapai.
\end{abstract}

Kata Kunci: UMKM wanita, kinerja, peningkatan laba, lembaga keuangan, informasi pasar, motivasi kerja, kemampuan wiraswasta

\section{Pendahuluan}

Sektor Usaha Mikro Kecil dan Menengah (UMKM) saat ini merupakan sektor strategis untuk meningkatkan pertumbuhan ekonomi, penciptaan lapangan kerja, dan pengentasan kemiskinan di Indonesia. Di Indonesia sendiri terdapat sebanyak 99,90 persen unit usaha yang berbentuk UMKM, dimana 98,8 persen dari jumlah UMKM tersebut didominasi oleh usaha Mikro. Disamping itu, UMKM juga telah menyerap 96,99 persen tenaga kerja dan menghasilkan 57,60 persen Produk Domestik Bruto (PDB) di Indonesia (Artanti, 2018). 
Deputi Gubernur Bank Indonesia Rosmaya Hadi menekankan pentingnya peran perempuan dalam kegiatan ekonomi di Indonesia, terutama dalam usaha UMKM tersebut. Menurut data yang dimilikinya, pengusaha wanita memberikan kontribusi sebesar 9,10 persen terhadap PDB Indonesia dan sumbangan ke ekspor masih di bawah 5 persen (Azka, 2018). Oleh sebab itu, peran wanita dalam roda perekonomian masih perlu didorong. Rosmaya lebih lanjut menjelaskan bahwa secara kepemilikan, UMKM mencapai 51 persen dari jumlah pengusaha kecil dan 34 persen dari usaha menengah dimiliki perempuan (Azka, 2018). Data Bank Dunia 2016 menunjukkan rasio kepemilikan usaha wanita di Indonesia lebih tinggi dibandingkan di dunia, terutama pada UMKM. Sehingga UMKM yang dijalankan oleh pengusaha wanita menjadi sangat penting dalam roda perekonomian di Indonesia.

Akan tetapi kebanyakan UMKM di Indonesia tidak mengalami kemajuan berarti dimana tidak mencapai tingkatan yang lebih tinggi. Sebagian dari mereka memiliki potensi berkembang lebih lanjut menjadi perusahaan besar tergantung pada pendiri dan wirausaha dari perusahaan-perusahaan tersebut. UMKM yang dijalankan para wanita juga mengalami banyak hambatan misalnya terbatasnya akses modal untuk perusahaan baru dan keterbatasan mereka untuk mengurus pula keluarga (Junianto, 2017).

Oleh sebab itu Pemerintah diharapkan dapat memberikan solusi untuk dapat meningkatkan kinerja UMKM agar mampu bersaing dan mencapai tingkatan lebih tinggi dibutuhkan pemahaman terhadap faktor-faktor yang menjadi penghambat pencapaian tersebut. Direktur Departemen Pengembangan UMKM Bank Indonesia Yunita Resmi Sari mengatakan permodalan menjadi faktor utama yang menghambat pertumbuhan UMKM (Nurhikmah, 2017). Oleh sebab itu, salah satu kebijakan yang dilakukan oleh Pemerintah adalah penyaluran pinjaman melalui Bank Indonesia (BI) kepada UMKM.

Perbankan saat ini sedang memasuki masa akhir untuk memenuhi porsi kredit UMKM. BI menetapkan bahwa seluruh bank wajib memenuhi porsi kredit UMKM dengan porsi sebesar 20 persen hingga akhir 2018. Apabila bank tidak menaati peraturan ini, maka BI akan memberikan sanksi tegas. Hal ini dikarenakan BI telah memberikan kelonggaran waktu bagi perbankan untuk memenuhi porsi kredit UMKM ini dengan cara mencicil sejak tahun 2015. Misalnya, bank hanya terkena kewajiban porsi kredit untuk UMKM sebesar 5 persen di tahun 2015 dan tetap wajib terus menaikkan porsi kredit kepada pelaku usaha UMKM sebesar 5 persen setiap tahunnya hingga di akhir tahun 2018 ini (Tribunnews, 2018). Akan tetapi bank-bank swasta mengalami kesulitan untuk mencapai target ini dikarenakan mereka memberikan pembiayaan yang tinggi pula kepada proyek infrastruktur yang didorong oleh proyek pemerintah. Misalnya, Jahja Setiaatmadja, Presiden Direktur PT Bank Central Asia Tbk (BCA) mengatakan bahwa BCA masih akan memberikan porsi kredit UMKM di level 16 persen (masih dibawah ketentuan BI) dikarenakan adanya permintaan yang cukup tinggi di segmen kredit lain seperti infrastruktur.

Menurut laporan BI, pada akhir Triwulan 1 tahun 2018, baki debet kredit UMKM naik sekitar 9,8 persen yang mencapai Rp. 987,5 trilliun. Namun demikian, penyaluran kredit belum mampu meningkatkan kinerja UMKM. Di Sulawesi Utara sendiri, data Dinas Koperasi Usaha Kecil Menengah Daerah Provinsi Sulawesi Utara menunjukkan bahwa terdapat 76.463 unit UMKM per 31 Desember 2016 dengan jumlah omzet berjumlah Rp. 12.879 .027 (dalam juta). Jenis usaha dari UMKM di Sulawesi Utara cukup beragam, mulai dari perdagangan kebutuhan rumah tangga, aneka industri olahan makanan, rumah makan, perdagangan alat dan aksesoris komunikasi, industri kerajinan kreatif, sampai aneka pelayanan jasa skala kecil dan menengah. Khususnya untuk Kota Manado, terdapat 18.608 unit UMKM per 31 Desember 2016 (Dinas Koperasi Usaha Kecil Menengah Daerah Provinsi Sulawesi Utara).

Aimasari dan Ghina (2015) dan Canedo, Stone, Black dan Lukaszewski (2014) menyatakan bahwa faktor motivasi merupakan faktor penting secara teoritis yang mempengaruhi kinerja kewirausahawaan dan oleh sebab itu perlu penelitian yang mendukung untuk mengekplorasi hal-hal apa yang mendorong pengusaha wanita untuk memulai, mengatur, dan mengelola bisnis mereka. Lebih lanjut, Tambunan (2002) menyebutkan bahwa aspek-aspek yang menjadi kekuatan dan kelemahan UKM adalah: (1) faktor manusia, yang terdiri dari motivasi yang kuat, penawaran tenaga kerja, etos kerja, produktivitas kerja, dan kualitas tenaga kerja; dan (2) faktor ekonomi/bisnis, yang meliputi bahan baku, akses sumber keuangan, nilai ekonomis, dan segmen pasar yang dilayani. Terlebih juga, kebanyakan literature tentang women entrepreneurs difokuskan pada negara-negara berkembang saja, hanya sedikit yang ada di negara-negara berkembang (Dzisi, 2008). Oleh sebab itu, penelitian ini dapat memenuhi literature gap yang ada. Adapun tujuan dari penelitian ini adalah untuk 
menganalisis faktor-faktor yang mempengaruhi kinerja pertumbuhan laba UMKM wirausaha wanita di Kota Manado

\section{Metode Penelitian}

Penelitian ini menggunakan metode kuantitatif. Metode kuantitatif adalah data penelitian ini berupa angka-angka dan analisis menggunakan statistik (Sugiyono, 2013). Sama halnya dengan Bryman (2006) menjelaskan bahwa quantitative approaches tend to focus on statistical analyses of quantifiable data. Pemilihan sampel menggunakan metode random sampling yang dilakukan pada UMKM wanita di Kota Manado. Jumlah sampel yang diambil adalah sebesar 66 responden UMKM wanita.

Metode analisis yang digunakan adalah metode kausalitas yang menjelaskan mengenai pengaruh akses atas lembaga keuangan, akses UMKM atas informasi pasar, motivasi kerja, serta kemampuan kewirausahaan terhadap peningkatan laba UMKM wirausaha wanita. Untuk melakukan analisis tersebut, digunakan alat analisis regresi berganda dengan metode Ordinary Least Square (OLS) untuk persamaan penelitian berikut ini.

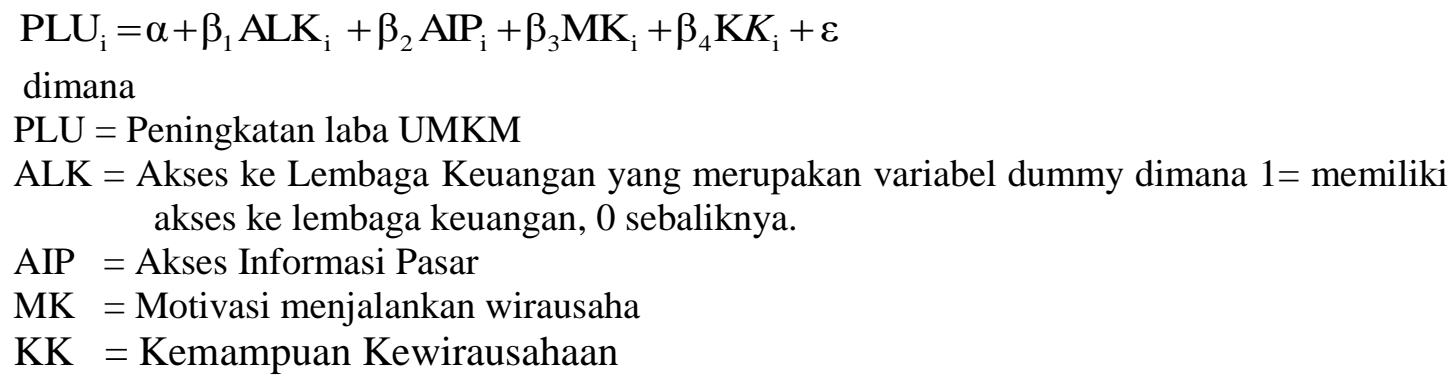

\section{Hasil Penelitian}

Hasil pengolahan data dengan menggunakan metode Ordinary Least Square (OLS) yang dijalankan dengan Program SPSS mendapatkan hasil sebagai berikut:

Tabel 1.1 Output SPSS

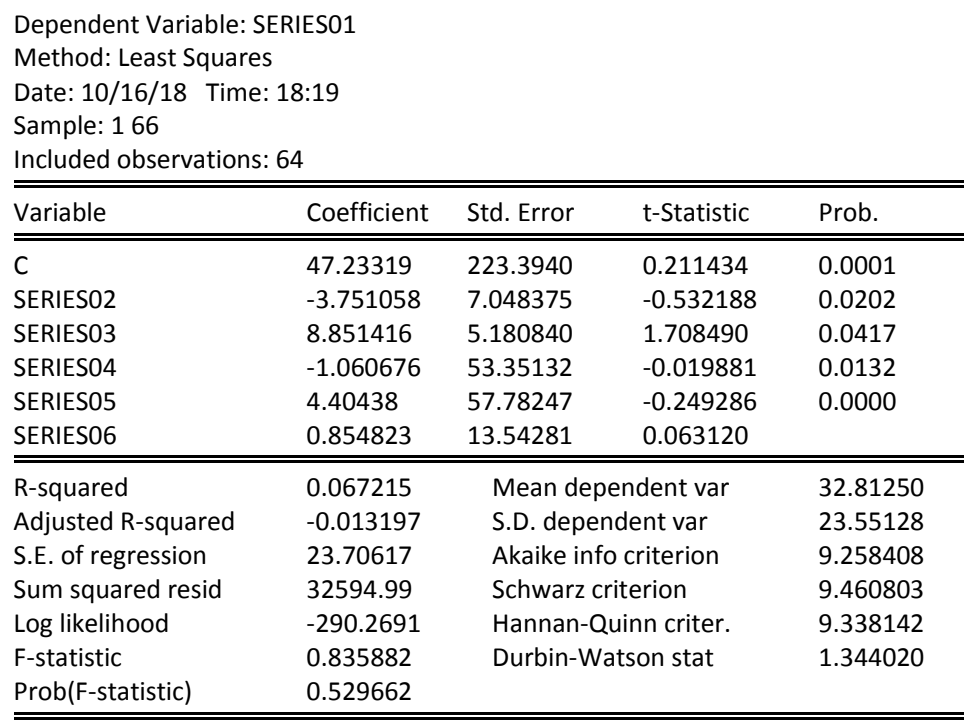

Keterangan:

Series 1: Kenaikan laba

Series 2: Menggunakan Kredit bank (ya atau tidak: jika ya 1)

Series 3: Akses Informasi Pasar

Series 4: Motivasi Kerja

Series 5: Kemampuan Wirausaha

Series 6: Series 4 x Series 5 
Pada Tabel 1.1 diperlihatkan bahwa variabel Akses ke Lembaga Keuangan, Akses Informasi Pasar, Motivasi Kerja, dan Kemampuan Kewirausahaan secara bersama-sama memiliki pengaruh signifikan secara statistik terhadap pertumbuhan laba UMKM di Kota Manado. Kondisi ini ditunjukan oleh nilai Prob (F-Statistic) sebesar 0,000 dimana lebih rendah dari 0,05. Ini juga menunjukan adanya kecocokan model (model fit) dari penelitian ini. Dengan demikian dapat dilanjutkan dengan uji parsial (uji-t) untuk tiap variabel penelitian.

Tabel 1.1 juga memperlihatkan hasil uji parsial (uji-t) atas variabel penelitian. Hasil pengujian parsial atas variabel Akses ke Lembaga Keuangan menunjukan bahwa nilai koefisien variabel tersebut sebesar negatif -3.751058. Sehubungan variabel Akses ke Lembaga Keuangan merupakan variabel dummy, maka hasil tersebut mengindikasikan bahwa pengaruh terhadap kinerja pertumbuhan laba dari UMKM yang memiliki akses ke lembaga keuangan lebih rendah dibanding UMKM yang tidak memiliki akses ke pasar. Variabel ini memiliki nilai probabilitas sebesar 0,0202 dimana lebih rendah dibanding 0,05 . Hal ini berarti bahwa variabel ini memberikan pengaruh yang signifikan secara statistik.

Tabel 1.1 juga memperlihatkan hasil uji parsial atas variabel Akses atas Informasi Pasar. Nilai koefisien variabel tersebut adalah positif 8.851416. Ini mengindikasikan bahwa variabel Akses ke Lembaga Keuangan memiliki pengaruh positif atau searah terhadap variabel Pertumbuhan Laba UMKM wirausaha wanita di Kota Manado. Namun demikian, pengaruh variabel tersebut signifikan secara statistik yang ditandai oleh probabilitasnya yang sebesar 0,0417 dimana lebih rendah dibanding level signifikan sebesar 0,05 .

Lebih lanjut, Tabel 1.1 juga memperlihatkan bahwa koefisien variabel Motivasi Kerja memiliki nilai negatif -1.060676. Hal ini berarti Motivasi Kerja memiliki pengaruh negatif terhadap pertumbuhan laba UMKM wirausaha wanita di Kota Manado. Akan tetapi probabilitasnya sebesar 0,0132 berada di bawah level signifikan sebesar 0,05 yang berarti bahwa pengaruh variabel tersebut signifikan secara statistik.

Akhirnya, hasil regresi sebagaimana ditampilkan pada Tabel 5.1 memperlihatkan bahwa koefisien variabel Kemampuan Kewirausahaan memiliki nilai positif sebesar 4.40438 dan nilai probabilitas variabel ini sebesar 0,000. Hal ini bermakna bahwa Kemampuan Kewirausahaan memiliki pengaruh positif dan signifikan secara statistik terhadap pertumbuhan laba UMKM wirausaha wanita di Kota Manado.

\section{Pembahasan}

Hasil penelitian menunjukan bahwa kinerja pertumbuhan laba dari UMKM wirausaha wanita di Kota Manado yang memiliki akses ke lembaga keuangan ternyata lebih rendah dibandingkan dengan mereka yang tidak memiliki akses ke lembaga keuangan. Hal ini menunjukkan akses ke lembaga keuangan menurunkan tingkat laba mereka yang disebabkan tingginya bunga yang harus mereka bayar sehingga pendapatan laba mereka menjadi menurun. Masalah lainnya adalah proses dan prosedur pengajuan pinjaman kredit dari bank yang panjang dan memakan waktu sehingga para pelaku UMKM mengalami ketidak efisienan waktu dan pembiayaan dalam menjalankan usaha mereka. Ditambah lagi dengan ketidak mampuan mereka dalam menghasilkan laporan keuangan yang sesuai dengan persyaratan yang diminta oleh pihak bank. Hal ini sesuai dengan penelitian dari Asnahwati dan Risman (2018) dan Suranta (2016) yang menyatakan bahwa terdapatnya kekurang mampuan dari pengelola bisnis UMKM dalam mengelola keuangan dan membuat pembukuan mereka secara baik seperti belum dapat tersusunnya atau tercatatnya transaksi penjualan secara akurat dan sistematis. Lalu masih bercampur aduknya keuangan pribadi dan keuangan wirausaha sehingga laporan keuangan yang dihasilkan masih belum akurat dan tidak memenuhi kriteria yang ditetapkan dan dapat menyebabkan kontrol dan pengelolaan keuangan yang masih lemah.

Akses informasi terhadap pasar memiliki pengaruh positif dan signifikan terhadap variabel Pertumbuhan Laba UMKM wanita di Kota Manado. Hal ini menunjukkan bahwa akses informasi terhadap pasar meningkatkan laba UMKM wanita di Manado yang berarti dengan diperolehnya informasi terhadap pasar dapat memberikan kesempatan peluang pasar yang lebih luas bagi wirausaha wanita sehingga dapat meningkatkan omzet penjualan mereka dan laba yang diperleh. Hal ini juga sejalan dengan notion dari Chetty dan Campbell-Hunt (2003) yang menyatakan informasi terhadap pasar dapat memberikan peluang pasar yang baru sehingga perusahaan dapat memperluas pangsa pasar penjualannya. Disamping itu akses pasar ini dapat memberikan informasi tentang kriteria- 
kriteria produk yang disukai oleh konsumen sehingga wirausaha dapat menjadi inovatif yang customer-oriented yang dapat meningkatkan nilai penjualan.

Hasil penelitian menunjukkan bahwa motivasi kerja para pelaku UMKM wanita berpengaruh negatif terhadap pertumbuhan laba. Hal ini berarti walaupun para wanita memiliki motivasi kuat untuk melakukan wirausaha mereka, mereka tetap harus memprioritaskan keluarga terutama anak-anak mereka. Sehingga seringkali mereka menutup tempat usaha (misalnya toko, warung ataupun rumah makan) mereka jika anak mereka sedang sakit ataupun mengurus suami dan orang-tua. Prilaku ini masih sesuai dengan adat budaya Indonesia dimana wanita didoktrin untuk menjadi ibu rumah tangga bukan pengusaha dan para suamilah yang harus berusaha dan bekerja untuk memenuhi kebutuhan keluarga mereka. Dengan tidak berjalannya secara total usaha mereka, sedangkan mereka tetap harus membayar biaya bunga yang berjalan maka dapat diprediksi laba usaha mereka dapat menurun. Hal ini sejalan dengan hasil penelitian dari Sayekti dan Sari (2018) dimana kelemahan para pengusaha wanita adalah mereka masih memiliki kondisi kodrat yang menyebabkan mereka tidak produktif, memiliki empati yang tinggi, takut gagal dan mengambil keputusan dengan banyak pertimbangan.

Yang terakhir adalah Kemampuan Kewirausahaan memiliki pengaruh positif dan signifikan terhadap pertumbuhan laba UMKM wanita di Kota Manado, hal ini berarti kemampuan wirausaha yang tinggi dapat meningkatkan pertumbuhan laba. Hal ini sesuai dengan notion dari Wong (2005:262) yang menyatakan bahwa pengetahuan dan kemampuan manajerial sangat berperan penting bagi kesuksesan UMKM yang mencakup a business imperative, a compelling vision and architecture, knowledge leadership, a knowledge creating and sharing culture, continuous learning, a welldeveloped technology infrastructure and systematic organisational knowledge processes.Hal ini tidaklah mengherankan, dengan memiliki kemampuan manjerial, akuntansi, marketing, dan operasional bisnis yang memadai, maka para wirausaha wanita tersebut dapat menjalankan bisnis mereka secara efisien, efektif dan menguntungkan.

\section{Kesimpulan dan Saran}

Hasil penelitian menunjukan bahwa kinerja pertumbuhan laba dari UMKM wirausaha wanita di Kota Manado yang memiliki akses ke lembaga keuangan ternyata lebih rendah dibandingkan dengan mereka yang tidak memiliki akses ke lembaga keuangan. Hal ini menunjukkan akses ke lembaga keuangan menurunkan tingkat laba mereka yang disebabkan tingginya bunga yang harus mereka bayar sehingga pendapatan laba mereka menjadi menurun, dan proses dan prosedur pengajuan pinjaman kredit dari bank yang berbelit.

Akses informasi terhadap pasar meningkatkan laba UMKM wanita di Manado yang berarti dengan diperolehnya informasi terhadap pasar dapat memberikan kesempatan peluang pasar yang lebih luas bagi wirausaha wanita sehingga dapat meningkatkan omzet penjualan mereka dan laba yang diperoleh. Varibel motivasi kerja para pelaku UMKM wanita berpengaruh negatif terhadap pertumbuhan laba. Hal ini disebabkan para pelaku usaha wanita tidak dapat melepaskan kodrat mereka sebagai ibu dan perempuan sehingga dapat menurunkan produktivitas mereka. Variabel lainnya yaitu kemampuan menjalankan wirausaha yang memadai dapat meningkatkan pertumbuhan laba. Hal ini berarti kemampuan manajerial dan keuangan yang baik dapat membantu kegiatan operasional UMKM wirausaha wanita secara efisien dan efektif sehingga laba optimal dapat tercapai.

Berdasarkan hasil penelitian ini, maka saran yang dapat diberikan adalah bahwa diharapkan pihak lembaga keuangan, perbankan dan pihak pemerintah untuk dapat membantu (memberikan keringanan) dalam pemberian pinjaman atau kredit dan pelatihan/seminar kepada para UMKM wirausaha wanita. Perlu juga diberikan pemahaman kepada pihak anggota keluarga mereka untuk dapat membantu meringankan beban kerja (dalam menangani urusan keluarga) dari kaum perempuan yang sedang menjalankan usaha supaya mereka dapat lebih berkonsentrasi dan produktif. Selain itu, perlu juga diberikan pengetahuan yang memadai dalam menjalankan bisnis mereka dalam bentuk pengetahuan manajemen, keuangan, marketing dan akuntansi untuk meningkatkan entrepreneurship skills para wanita tersebut.

\section{Daftar Pustaka}

Aimasari, Nina \& Ghina, Asri (2015), Analisis Faktor-Faktor yang memotivasi wanita untuk menjadi wirausaha (Studi Pengusaha Wanita UMKM di Kota Bandung tahun 2015), e-Proceeding of Management, 2 (3), 2795-2799. 
Anggadwita, Grisna and Qaanita Yuuha Mustafid (2014), Identification of Factors Influencing the Performance of Small Medium Enterprises (SMEs), Procedia-Social and Behavioral Sciences, 115 (2014), 415-423.

Artanti, Anissa Ayu (2018). Perempuan Potensi Penggerak UMKM. http://ekonomi.metrotvnews.com/mikro/eN4Xwq1N-perempuan-potensi-penggerak-umkm diakses pada tanggal 12 November 2018.

Armario, J. M., Ruiz, D. M., \& Armario, E. M. (2008). Market orientation and internationalization in small and medium-sized enterprises. Journal of Small Business Management, 46(4), 485-511.

Asnahwati, A., \& Risman, R. (2018). Model Tata Kelola Keuangan Usaha Mikro Kecil Menengah (UMKM) Wanita. Jurnal Daya Saing, 4(2), 259-268.

Azka, Rinaldi Mohammad (2018). Ini Pentingnya Perempuan Berperan di UMKM. http://industri.bisnis.com/read/20180721/12/819124/ini-pentingnya-perempuan-berperan-di-umkm diakses pada tanggal 12 November 2018.

Bank Indonesia (2015). Profil Bisnis UMKM, bekerja sama dengan Lembaga Pengembangan Perbankan Indonesia (LPPI).

Bank Indonesia (2018). Laporan Perkembangan Kredit UMKM Triwulan 1 tahun 2018. https://www.bi.go.id/id/umkm/kredit/laporan/Pages/Laporan-Perkembangan-Kredit-UMKMTriwulan-I-2018.aspx diakses pada tanggal 12 November 2018.

Bhaskaran, S. (2006). Incremental innovation and business performance: small and medium-size food enterprises in a concentrated industry environment. Journal of Small Business Management, 44(1), 64-80.

Bryman, Alan (2006), Integrating quantitative and qualitative research: how is it done?. Qualitative research, 6(1), 97-113.

Canedo, C. J., Stone, D. L., Black, S.L., \& Lukaszewski, K.M (2014). Individual factors affecting entrepreneurship in Hispanics. Journal of Managerial Psychology, 29(6), 755-772.

Chetty, S., \& Campbell-Hunt, C. (2003). Explosive international growth and problems of success amongst small to medium-sized firms. International Small Business Journal, 21(1), 5-27.

Dinas Koperasi Usaha Kecil Menengah Daerah Provinsi Sulawesi Utara (2016). Rekapitulasi Data Perkembangan UMKM Kabupaten/Kota (per 31 Desember 2016). http://diskopukm.sulutprov.go.id/data_statistik.php diakses pada tanggal 12 November 2018.

Dzisi, S. (2008). Women entrepreneurs in small and medium enterprises (SMEs) in Ghana (Doctoral dissertation, Swinburne University of Technology, Australian Graduate School of Entrepreneurship).

Gorman, G., Hanlon, D., \& King, W. (1997). Some research perspectives on entrepreneurship education, enterprise education and education for small business management: a ten-year literature review. International small business journal, 15(3), 56-77.

Junianto, Beno (2017). 60 persen UKM didominasi wanita, tak punya akses pinjaman. https://www.viva.co.id/digital/startup/896651-60-persen-ukm-didominasi-wanita-tak-punya-aksespinjaman diakses pada tanggal 12 Februari 2018. 
Luciana, M., \& Anggadwita, G. (2018). Analisis Faktor-faktor Yang Berpengaruh Terhadap Niat Berwirausaha Dengan Pendekatan Theory Of Planned Behavior (studi Kasus Pada Wirausaha Muda Wanita Umkm Kelompok Usia 17-25 Tahun Di Kota Bandung). eProceedings of Management, 5(2).

Nurhikmah (2017). Penyaluran Kredit Perbankan Untuk UMKM Masih Rendah. http://bisnis.rakyatku.com/read/74920/2017/11/21/penyaluran-kredit-perbankan-untuk-umkmmasih-rendah diakses pada tanggal 12 November 2018.

Sayekti, R. N. S., \& Sari, N. K. (2018). Analisa Strategi Peranan Wanita UMKM dalam Peningkatan Perekonomian di Kecamatan Ngantang, Kabupaten Malang (Pendekatan Analisa SWOT). Referensi: Jurnal Ilmu Manajemen dan Akuntansi, 6(1), 36-45.

Sugiyono. (2013), Metode Penelitian Kuantitatif Kualitatif dan R\&D. Bandung: Alfabeta.

Suranta, S., Perdana, H. D., \& Syafiqurrahman, M. (2016). Usaha Kripik Nabati: Manajemen Usaha dan Proses Produksi (Studi pada Kelompok Wanita Tani (KWT) Sejahtera Desa Kopen Teras Boyolali). SEMAR (Jurnal Ilmu Pengetahuan, Teknologi, dan Seni bagi Masyarakat), 4(2).

Tambunan, Tulus T.H. (2002), Usaha Kecil dan Menengah di Indonesia: Beberapa Isu Penting, Salemba Empat, Jakarta.

Tribunnews (2018). Bank Kesulitan Penuhi Porsi UMKM. http://manado.tribunnews.com/2018/06/29/bank-kesulitan-penuhi-porsi-umkm diakses pada tanggal 12 November 2018.

Wong, Kuan Yew (2005). Critical success factors for implementing knowledge management in small and medium enterprises, Industrial Management \& Data Systems, 105(3), 261-279. 